\title{
MEMÓRIA, NARRATIVA E O TRÁGICO MODERNO
}

\section{Memory, narrative and the modern tragic}

\author{
Elen de Medeiros \\ Universidade Federal de Minas Gerais - UFMG
}

Resumo: O ponto central do artigo é a memória e o que dela se projeta como narrativa na construção dramatúrgica de Nelson Rodrigues, Carlos Alberto Soffredini e Luís Alberto de Abreu. Por meio do processo de reconstrução fabular, uma certa ideia de tragicidade que se alinha à noção sustentada na modernidade será consolidada. Os três autores e as peças aqui dispostas estão ligados a um processo memorialístico fragmentado de constituição da narrativa e, nesses casos, representação de um aspecto trágico do homem moderno.

Palavras-chave: memória; tragicidade; modernidade; dramaturgia brasileira; teatro.

Abstract: The central point of the article is the memory and its projections as narrative in the dramaturgical construction of Nelson Rodrigues, Carlos Alberto Soffredini and Luís Alberto de Abreu. Through the mnemonic process, a certain idea of tragicity that aligns with the notion sustained in modernity will be consolidated. The three authors and the pieces studied are linked to a memorialistic process fragmented of the constitution of the narrative and, in these cases, representation of a tragic aspect of modern man.

Keywords: memory; tragicity; modernity; Brazilian dramaturgy; theater.

\footnotetext{
${ }^{1}$ Pesquisa financiada com recursos do edital ADRC/PRPq/UFMG.

Moringa Artes do Espetáculo, João Pessoa, UFPB, v. 10 n. 1, jan-jun/2019, p. 149 a 162

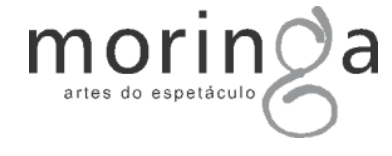




\section{Incertezas do real}

A incomum aproximação que se pode estabelecer entre Vestido de noiva, de Nelson Rodrigues, De onde vem o verão, de Carlos Alberto Soffredini, e O livro de Jó, assinada por Luís Alberto de Abreu para o espetáculo do Teatro da Vertigem, explica-se pelo uso que os dramaturgos fazem de um mesmo dispositivo para levar as narrativas para o campo das incertezas por meio da aporia narrativa. Ou seja, o que talvez seja o ponto unificador das dramaturgias que se agrupam neste texto é a incerteza do real e a impossibilidade de resposta às questões principais lançadas: as peças todas apontam para a imprecisão da fábula, partindo de um mesmo dispositivo, a reconstrução da memória. E, nelas, esse processo de rememoração leva à reconstituição de um fato trágico sem, no entanto, elucidar a dubiedade sobre a qual se instala a narração. Estamos, portanto, lidando com a memória - especialmente a psíquica - como dispositivo dramatúrgico que rompe com a reconstrução mimética e verossímil de uma suposta realidade, deslocando o lugar da narração para o irreal: o sonho e o desvario.

O uso de um monólogo interior, nos dois primeiros casos, como recurso de exteriorização de seus sonhos e desejos; e da mitologia bíblica, no segundo, para compor a alegoria moderna da tragicidade humana, tem como principal meio de deslocamento da realidade a memória. Este feito provoca uma enunciação narrativa em destaque e que é também o desencadeador do sentido trágico nas peças, que se manifestará por meio da morte, do isolamento, do autoaniquilamento.

Para essa noção de trágico moderno, é compreensível que lidemos com sua noção na contemporaneidade, um pouco na esteira do pensamento de Williams, em sua Tragédia moderna (2012), e acompanhando os passos de Szondi no seu Ensaio sobre o trágico (2004). Estamos corroborando a ideia de que a modernidade pode propiciar a constituição de um gênero trágico, desenhado à sua maneira, conforme a relação que estabelece: seja uma tragédia social, privada ou mesmo 
individual. Estamos diante de possibilidades de novas formulações da tragédia na modernidade e na contemporaneidade. Desde o surgimento da filosofia do trágico (cf. Szondi, 2004), este sentido permanece como consequência de relações conflituosas ou do tensionamento de forças opostas encarada por formas diversas.

Fundada por Schelling de maneira inteiramente não-programática, ela [a filosofia do trágico] atravessa o pensamento dos períodos idealista e pós-idealista, assumindo sempre uma nova forma. (SZONDI, 2004, p. 24)

Para muitos dos autores investigados por Williams, viver e sobreviver é uma forma de luta, seja diante de um íntimo que se encaminha à destruição, seja na relação desse vetor pessoal com a sociedade em que está, o que normalmente provoca conflitos. O que nossos autores processam é potencialmente a tragicidade do homem comum, em relação consigo mesmo, em uma condição (social, psíquica, individual) bastante particularizada. De todo modo, podemos vislumbrar nas formas construídas a percepção de um universo de conflitos e derrocada, provocada por motivos variados, mas que se colocam diante da singeleza do homem brasileiro moderno.

Para poder chegar a esse trágico do homem comum, reconhecer a forma como os autores constroem a fábula é um meio que aqui nos interessa, na medida em que estamos lidando justamente com as estruturas modernas e contemporâneas do teatro brasileiro. $\mathrm{E}$, para isso, recorremos a Sarrazac, que se dedica a reconhecer os dispositivos utilizados por alguns autores e que colocaram um problema à convencional construção fabular. Sintetizando os modos de operar este elemento, o crítico resume duas fórmulas bastante simples de lidar com a intriga:

a) O drama não é mais representado, o que é representado é um voltar-se para o drama (pensamento elaborado especialmente a partir de Seis personagens à procura de um autor, de Luigi Pirandello);

b) O drama da vida substitui 0 drama na vida. (SARRAZAC, 2013, p. 76)

O crítico coloca em destaque a recorrente mudança de paradigma 
na construção da fábula moderna, que agora já não mais se preocupa em lidar com as grandes peripécias dos heróis, mas dar conta de uma vida comum sem sobressaltos, uma vida que se estende por um déficit de ações. E muitas vezes a melhor forma de lidar com essa extensão toda é justamente não representá-la, colocá-la em suspenso, em uma nãoação. "A escolha - poética e política - é a da exibição do detalhe. Ele implica uma recusa não da fábula, mas do que é preciso chamar de 0 fabulismo: uma fábula ossificada, construída a priori." (SARRAZAC, 2013, p. 91)

\section{Detemo-nos precisamente} nesse aspecto do detalhe (e da fragmentação, da memória entrecortada), que lida com toda a extensão da narrativa, porque isso significa aceitar que o que se vê é apenas parte da "realidade": "Não se vê mais a realidade, vê-se um pouco da realidade" (Müller apud Sarrazac, 2013, p. 90). Interessa-nos observar - quanto essa predileção pelo detalhe potencializa o deslocamento do real, a partir da reconstrução da memória, em Vestido de noiva (1943), de Nelson Rodrigues, De onde vem o verão (1989-1990), de Carlos Alberto Soffredini, e O livro de Jó (1995), de Luís Alberto de Abreu.

\section{O lugar da memória}

A dramaturgia de Nelson Rodrigues é amplamente amparada pelo recurso memorialístico: trata-se de um teatro da memória. Em toda sua obra dramática existe uma memória a ser reconstruída: algo do passado que se faz presente, que atormenta suas personagens e que joga constantemente a dúvida sobre o fato narrado, ao mesmo tempo em que despedaça a narrativa e joga com os detalhes na reconstrução de um todo que jamais haverá. Geni, de Toda nudez será castigada, está morta e, a partir de flashback, narra os fatos que aconteceram entre ela, Herculano, Serginho e Patrício; Sônia, em Valsa $n^{\circ} 6$, é uma jovem de 15 anos atormentada pela lembrança e pela necessidade de reconstruir sua memória, tal como Alaíde, de Vestido de noiva; Boca de Ouro, da peça homônima, só passa a existir a partir da narrativa memorialística de Guigui a Caveirinha; Zulmira, protagonista de 
A falecida, carrega consigo uma memória de traição, e descoberta dela pela prima, que precisa ser superada por um evento grandioso, sua morte; Arandir, em $O$ beijo no asfalto, é assombrado durante toda a peça pelo gesto de ter beijado um atropelado no meio da rua, ato que antecede o início da ação dramática. Assim, embora algumas das observações que se seguem possam ser estendidas às 17 peças que compõem sua obra teatral, aqui vamos nos deter especificamente em Vestido de noiva, que dá maior corpo aos pressupostos que seguimos.

Alaíde é uma mulher que, à beira da morte, precisa recompor sua história, seu passado, e para isso conta com a ajuda de Clessi, prostituta do início do século XX alter ego da protagonista -, que a auxilia nos caminhos de reconstrução dos fatos. Nesse percurso, um tanto sinuoso, Alaíde se defronta com as vontades recalcadas, os medos e o anseio por uma libertação de seus desejos, sem deixar de visitar lugares e espaços inusitados, tais como o lupanar em que supostamente Clessi trabalhava e o velório da prostituta. Como bem observou

Antonio

Guedes

(2010/2011, p. 387-388) sobre os planos narrativos utilizados para a estruturação da peça: "Há um sentido na história a ser contada, mas o principal é compreender que, em Nelson, essa história deverá ser revelada a partir de uma estrutura que deve mostrar-se como estrutura" (Grifo do autor). Ou seja, a estrutura dramática de Vestido de noiva é mais importante do que a história a ser contada.

Para acompanhar os passos de Alaíde, protagonista de Vestido de noiva, na reconstrução de sua memória, temos de olhar atentamente os pequenos dados lançados na peça, especialmente porque eles parecem evidenciar um jogo constante entre realidade e ficção dentro do próprio universo ficcional existente na obra teatral. Além disso, atentar-se a essa construção de sua dramaturgia implica tomar conhecimento de uma poética delineada pelo dramaturgo, a que Flora Sussekind (1977, p. 37) se referiu como "fundo falso":

Nelson faz uso dessas relações [interpessoais], desses mecanismos [de articulação de 
conceitos] e desses temas [da dramaturgia ocidental] de uma maneira insólita, apontando para o fundo falso que procuram encobrir. Desnudando este fundo falso, onde se articulam conceitos, temas e relações, o teatro de Nelson Rodrigues vai obrigar o espectador a duvidar dessas mesmas ideias e da própria imagem construída sobre elas. (SUSSEKIND, 1977, p. 37)

Como uma homenagem à mais importante obra do dramaturgo pernambucano, Carlos Alberto Soffredini escreveu $\mathrm{De}$ onde vem o verão (cf. MEDEIROS; TORTORELLA, 2017), colocando em cena uma mulher, Marlene, parada à janela de sua casa com seus devaneios de verão, a partir do que podemos ver um processo de construção, desconstrução e reconstrução da ação, tal como há em Vestido de noiva. Afora os muitos elementos que dialogam entre as duas peças, o que nos toca como elemento de observação é o uso que ambos os autores fazem da memória como dispositivo dramatúrgico de fragmentação da narrativa, dando por meio disso uma potência trágica às fábulas.

Se de um lado temos uma fábula fragmentada, multifacetada pelas leituras que elas possibilitam, dada a abertura do jogo narrativo que as constituem, ao mesmo tempo essa estrutura fabular não é aniquilada, mas colocada em foco pelo detalhe. Em ambas as peças o recorte proposto é pelo recurso prosaico: em Vestido de noiva, a cena que antecede o casamento de Alaíde e Pedro, momento em que a noiva se prepara para a cerimônia; já em De onde vem o verão, a cenachave para explorar os meandros da memória é a cena em que Natalino aparece de toalha, saído do banho, e encontra Marlene e Alicinha na sala da casa. Essas cenas são repetidas, reconstruídas à exaustão, com a minúcia de detalhes antes não expostos, para potencializar os caminhos obscuros da memória como dispositivo de narração.

As narradoras protagonistas são Alaíde e Marlene, mulheres que, na ânsia de uma satisfação da vida comum, carregam consigo a potência trágica, que só ganhará destaque no texto dramático pelo recurso memorialístico. Ambas se embrenham no universo pouco conhecido das memórias e dos desejos para romper com o marasmo 
que as sustenta na sua realidade, dando ênfase para a expansão de um eu íntimo que é investigado ao longo da ação dramática. Para isso, passeiam por momentos de alucinação, num espaço temporal muito pouco delineado, praticamente indefinido: Alaíde entre o atropelamento e a morte; Marlene entre a janela de casa e o verão enunciado pelas andorinhas. Nesse processo mnemônico, o jogo entre realidade, memória e alucinação se torna cada vez mais estreito, mesclando os planos narrativos. De influência claramente expressionista, as peças colocam em primeiro plano um nível intrasubjetivo das protagonistas, projetando ao palco seus desejos, medos e anseios. Se, no entanto, o foco dado às protagonistas (por meio deste intra) já é um elemento de aproximação com a fábula - mas cada vez mais explorado ao longo do século XX -, é a forma escolhida, de desconstrução e reconstrução dos fatos, que se torna 0 ponto forte dessas dramaturgias, sendo ela mesma parte da própria narrativa.

Estamos lidando, bem precisamente, com um teatro íntimo, nos termos de Jean-Pierre Sarrazac (1989, p. 67): um teatro do eu e um teatro do mundo que entram em tensão. "Lugar da intimidade consigo mesmo e com os espetadores, onde teatro do eu e teatro do mundo são colocados em tensão". 2 Um eu que é exposto a partir desse dispositivo em comum, o mnemônico, do qual vão se valer para explorar o mais "interior do interior", que não é precisamente o segredo, mas aquilo que se projeta contra o outro, marcando um conflito entre esse mundo interno e o mundo externo. Aqui a memória serve bem claramente para as investigações desse universo subjacente ao eu e à existência "realista". Ambas são espectadoras de si mesmas, duplicando-se em cena para observar, de forma passiva, o que as compõe.

\section{O trágico metafísico}

O livro de Jó, texto da trilogia bíblica do Teatro da Vertigem, não parte necessariamente de uma lembrança psíquica, um processo de reconstrução mnemônico. De todo modo, o texto joga com a dúvida da

${ }^{2}$ Tradução nossa. 
representação verossímil ao juntar a retomada metafísica do mito bíblico de Jó com a encenação em um hospital desativado. Dessa forma, a dramaturgia de Luís Alberto de Abreu lida com a abertura da forma e da representação

mimética, especialmente pela inserção do euépico constante e distanciado do personagem. Já na rubrica de abertura da peça, há a indicação dessa ambiguidade: "A ação se passa num hospital contemporâneo, e Jó talvez seja um doente que a proximidade da morte faz perder a razão. Ou talvez não." (Grifos nossos).

Uma das potências da peça que se complexifica na medida em que o texto ganha uma encenação hiper-realista (cf. FERNANDES, 2010) - é exatamente a imprecisão da narrativa, que se insere justamente na possibilidade de reconstrução da fábula pela voz de um narrador que perdeu a razão. Dúbia, a representação do mito bíblico na condição social contemporânea ganha ares memorialísticos quando mestre, contramestre, ator-Jó, ou a atrizmatriarca etc., passam a narrar os fatos num tempo passado, pertencente à memória cultural cristã:
MESTRE
$E$ foi neste deserto que ocorreu o drama de um tempo ido
$\mathrm{E}$ de homens tão parecidos com os homens de agora
Andou pelo mundo outrora um homem chamado Jó
Deus, na aurora dos tempos, ainda não estava morto
como acontece agora
E Jó caminhava na senda de Deus que não era morto
E era o único ser que o justo Jó temia. (ABREU, 2002)

A imprecisão da fábula se desenvolve ao longo de toda a peça, dando possibilidades de olhar para a história daquele

homem adoentado/fiel. E quando, ao acompanhar toda a trajetória de Jó em um movimento ascendente no hospital, finalizando com sua morte em uma sala de cirurgia, ${ }^{3}$ a dúvida permanece incitada no discurso dramatúrgico:

\footnotetext{
3 As referências cênicas, de ascensão e finalização em uma sala cirúrgica, não estão explícitas no texto dramatúrgico, mas compuseram o espetáculo original do Teatro da Vertigem, estreado em 1995 no Hospital Humberto I, em São Paulo.
} 
Mestre

E para os que crêem Deus aqui se manifestou, desceu e habitou o homem.

Contramestre

E para os que não crêem a doença enlouqueceu Jó desde o princípio de nossa narração. E Jó viveu sonho e delírio sem, até a morte, recuperar a razão.

Mestre

E para os que crêem, depois desses acontecimentos, Jó ainda viveu.

Contramestre

$E$ para os que não crêem a história acabou.

E a mulher de Jó peregrinou

Por revolto mar

E fez de si própria seu porto

Até naufragar. (ABREU, 2002)

Existe uma potência discursiva em $O$ livro de Jó que lida com as incertezas metafísicas do contemporâneo, interpelando seu espectador a questionar-se se está perante um homem doente e sua tragédia pessoal, isolado e abandonado em um hospital próximo à morte, diante do que nada pode fazer senão questionar a sua fé; ou perante a representação do mito bíblico de Jó, que, na esperança de ser compreendido por Deus, mantém sua fé diante das vicissitudes, cuja força trágica se esvai diante da possibilidade do perdão, embora ainda se percebam os conflitos contundentes do isolamento do homem. A ambiguidade do texto é o que desenha a força lírica do espetáculo, em conjuntura com a presença forte das leituras do cotidiano contemporâneo. Estamos, de todo modo, em confronto com a incerteza do que vemos, absorvendo apenas uma parte - uma pequena parte - do que se entende por verdade. Nada pode ser afirmado, nem negado.

Há, sobremaneira, nesse diálogo intrínseco, nesse jogo entre o mítico cristão e o hiper-realismo contemporâneo, a configuração da tragédia potencial do texto: 0 isolamento do homem na conjuntura limite de sua vida, a busca por um sentido e de razões para sua dor e sofrimento diante daquilo que se busca metafisicamente, a sobrevivência, e a consequente perda de toda esperança. É, portanto, o delineamento de um trágico metafísico lendo as (im)potências do mundo moderno.

\section{Morte, fatalidade, tragicidade}

Os três casos aqui tomados de exemplos tratam não de um drama na vida, mas de um drama da 
vida, para recorrer novamente ao pensamento crítico de Sarrazac. Ou seja, trata-se antes de tudo da ampla projeção, reflexão e questionamento sobre os aspectos que tangem a vida como um todo, que se colocam como discurso complexo a partir da parte, do detalhe. É um voltar-se, sobretudo, para a catástrofe desse drama da vida nas peças, via recorte do cotidiano dos protagonistas: seja pela busca incessante de um eu íntimo, seja pela busca do divino, um ser metafísico em ambos os casos.

A morte - e o seu desencadeamento pela memória também se repete nessa inusual aproximação: investigar os motivos que a desencadearam (ou desencadearão) torna-se vórtice das ações dos protagonistas, conferindoIhe um isolamento trágico peculiar da modernidade. Essa ideia de uma tragédia moderna ser potencializada por fatores inerentes à nossa sociedade, e a luta que se estabelece contra ela, pauta o pensamento de Raymond Williams, em Tragédia moderna. Em um dos modelos analisados pelo estudioso, o de tragédia privada, ele faz o seguinte traçado:
Há um tipo de tragédia que começa com o homem nu e desamparado. Toda energia primária centra-se nesse ser isolado que deseja, se alimenta e luta a sós. A sociedade é, na melhor das hipóteses, uma instituição arbitrária para impedir que essa horda de criaturas destruam umas às outras. $E$, quando essas pessoas isoladas se encontram nos chamados relacionamentos, as suas trocas são, inevitavelmente, formas de luta. (WILLIAMS, 2012, p. 143)

Bastante moderna e contemporânea - sobretudo se pensarmos na imagem de Jó, desolado e isolado -, essa configuração de tragédia ajuda a compreender parte do sentido exposto nas peças aqui em questão, embora o que as unifique em um grupo seja 0 modo como elas expõem essa tragicidade: pelo uso da memória (psíquica ou mítica). E a morte, que não é o símbolo da tragédia, mas tampouco se distancia dela, também perfaz seu trajeto nessas dramaturgias. Existe, em certa medida, uma projeção das personagens à morte a partir justamente da reconstrução da memória, dessa busca de compreensão da existência, desse drama da vida. 
O desejo da morte pode ser menos forte, ou mais profundamente disfarçado, mas, quando alcançado é obviamente permanente. (...) A tempestade que acomete a vida não é necessariamente desencadeada por qualquer ação pessoal, ela começa quando nascemos, e o nosso abandono a ela é absoluto.

A morte, por oposição, é uma espécie de realização, capaz de trazer, comparativamente, ordem e paz. (WILLIAMS, 2012, p. 144)

Talvez o conforto do fim que simboliza a morte perpasse a expectativa dos personagens, dando ensejo ao trajeto percorrido pelo emaranhado da memória. $A$ tragicidade, portanto, não está apenas na morte em si, mas no caminho até chegar a ela. A morte está aqui como elemento do sublime, alcançado após um percurso sinuoso de investigação e questionamento (de si, do divino). Alaíde precisa recompor sua memória e buscar efetivamente sua identidade para, enfim, morrer; enquanto Jó, na busca incessante pelas respostas às suas dores e pelo encontro com o Divino, deve sucumbir - ou, como doente, após um longo percurso de convalescência, ele finalmente encontra o seu conforto na morte. Marlene, caso à parte, não percorre um trajeto para ter sua morte decretada ao fim: ao contrário, é no emaranhado de sua memória que se perde a notícia da morte (ou não) de Natalino. Mas seria, por fim, o apaziguamento de suas angústias de verão.

\begin{abstract}
Representar essa impossibilidade de o ser humano viver sua própria morte, e assim realmente morrer, torna-se um dos objetivos e um dos desafios da arte. E do teatro, parece que mais ainda do que outras práticas artísticas, uma vez que ele oferece uma forma de apresentação sensível, um espaço inteiramente dedicado à presença e à convocação. ${ }^{4}$ (NAUGRETTE, 2004, p. 101)
\end{abstract}

A memória, capciosa, tendenciosa, leva os protagonistas ao encontro com a morte, deles ou de outrem. Sobretudo, a imprecisão dessa memória constrói a fábula como uma aporia: como aquilo que não se resolve, que trata da impotência, desde a tragédia grega é sintoma do trágico. Alaíde precisa recuperar sua memória justamente para morrer; Marlene refaz na sua memória como matou - e se matou Natalino; Jó perece num hospital até o momento de sua morte, quando

\footnotetext{
${ }^{4}$ Tradução nossa.
} 
então terá seu encontro com o divino que tanto almeja. De forma não regular, mas justamente colocando a noção de verdade e dando relevo à impossibilidade de traçar uma linha reta entre pergunta e resposta, em choque com a dubiedade do exposto em cena, as peças lidam com a fatalidade da morte diante do que reconstroem memorialisticamente, conferindo assim a tragicidade inerente às narrativas: o trágico é o imponderável, o beco sem saída em que se veem as protagonistas diante do que a memória lhes oferece.

\section{Dramas vividos}

O que nos interessa nessa aproximação das peças, mais do que um esforço anacrônico de entender como elas lidam com as narrativas e a reconfiguração da tragédia na modernidade, é antes perceber os dispositivos dramatúrgicos de que lançaram mão os autores em diferentes épocas, e de formas particulares, para a construção de suas obras. Inequivocamente, são dramaturgos de poéticas dramatúrgicas distintas, todos os três com opções variadas, mas que em certa medida optam pelos mesmos recursos para a elaboração de uma dramaturgia que dialogue com o seu tempo, com as potências de uma investigação, reformulando assim um mesmo elemento e colocando em destaque, a seu modo, forças questionadoras do formato dramático convencional.

Catherine Naugrette (2004) observa que, a despeito de o teatro moderno (e pós-moderno) não ser mais fundado sobre a ideia de catarse nem ser regido segundo as normas do "belo animal" aristotélico, cabe a pergunta se sua função primeira não é despertar hoje, mais do que nunca, o "sentido do humano":

Como indica a presença
assombrosa de um campo lexical
do humano e da humanidade nos
textos de estética teatral
contemporânea, assim como o
recurso recorrente no discurso dos
homens de teatro a esses dois
termos e suas antinomias, a
humanidade (e/ou a
desumanidade) do homem é o
cerne da problemática estética do
teatro atual. ${ }^{5}$ (NAUGRETTE, 2004,
p. 142)

5 Comme l'indiquent la présence quase obsédante d'un champ lexical de l'humain et de l'humanité dans les textes d'esthétique théâtrale contemporains ainsi que le recours récurrent dans le discours des homme de théâtre à ces deux termes et à leurs 
O ponto crucial, portanto, dessa nossa investigação está atrelado à formulação estética que cada uma das obras e dos autores aborda, com a reutilização de elementos em comum, para trazer à superfície da arte aquilo que é inerente a si: o sentido do humano. São dramas, no sentido dúbio do termo, vividos em cena, função que o teatro moderno e contemporâneo jamais anulou e, em grande parte, da qual também não se distanciou.

Recebido em 11/06/2018

Aceito em 31/08/2018

\section{Referências Bibliográficas}

ABREU, Luís Alberto. O livro de Jó. In: Trilogia bíblica. São Paulo, PubliFolha, 2002.

FERNANDES, Sílvia. Teatralidades contemporâneas. São Paulo, Perspectiva, 2010.

GUEDES, Antonio. A precisão das falas e a concretude cênica em Nelson Rodrigues. In : Folhetim n. 29. Rio de Janeiro, Teatro do Pequeno Gesto, 2010/2011.

NAUGRETTE, Catherine. Paysages dévastés: le théâtre et le sens de
I'humain. Belval, Éditions Circé, 2004.

MEDEIROS, Elen de; TORTORELLA, Maria Emília. Modernidade dramática em dois tempos: Carlos Alberto Soffredini e uma homenagem a Nelson Rodrigues. In: Estudos de Literatura Brasileira Contemporânea. n.50, jan/abr. 2017. pp.468-487.

RODRIGUES, Nelson. Teatro completo. 4. vols. Rio de Janeiro, Nova Fronteira, 2004.

SARRAZAC, Jean-Pierre. Sobre a fábula e o desvio. Trad. e org. de Fátima Saadi. Rio de Janeiro, 7 Letras/Teatro do Pequeno Gesto, 2013.

SARRAZAC, Jean-Pierre. Théâtre intimes. Paris, Actes Sud, 1989.

SOFFREDINI, Carlos Alberto. De onde vem o verão. Cópia mimeo.

SUSSEKIND, Flora. Nelson Rodrigues e o fundo falso. In: I Concurso nacional de monografias - 1976. Brasília, MEC/SNT, 1977.

SZONDI, Peter. Ensaio sobre o trágico. Trad. Pedro Süssekind. Rio de Janeiro, Jorge Zahar, 2004.

WILLIAMS, Raymond. Tragédia moderna. São Paulo, Cosac Naify, 2012. 
Moringa Artes do Espetáculo, João Pessoa, UFPB, v. 10 n. 1, jan-jun/2019, p. 149 a 162

\section{morinda}

